\title{
The Viking Hypothesis from a Dialectologist's Perspective
}

\author{
Bernd Kortmann \\ University of Freiburg \\ bernd.kortmann@anglistik.uni-freiburg.de
}

\begin{abstract}
The Viking Hypothesis neglects (i) the significant degree of stability from Old to Middle (and even Modern) English grammar and (ii) parallel, but independent, developments not induced by North Germanic in the grammars of continental West Germanic dialects.
\end{abstract}

\section{Keywords}

historical syntax - language contact - history of English - Germanic

The author of this commentary is not a historical linguist, but someone with experience in surveying large-scale typological (i.e., morphosyntactic) profiles of English dialects and varieties of English around the world (cf. the World Atlas of Varieties of English, henceforth WAVE; Kortmann and Lunkenheimer, 2012, 2013). This comment explores how the typological profiles of Old, Middle and Early Modern English (henceforth oE, ME, EModE) fare if compared with each other and their present-day "offspring," notably the English English dialects (especially the ones from the North of England). This method helps us approximate the spontaneous spoken language of medieval England with the help of a large set of morphosyntactic features found across contemporary English varieties ( 235 features distributed across a dozen domains of grammar; cf. ewave-atlas.org), which in turn allows us to get a grasp of the morphosyntactic systems of OE, ME and EModE and to determine degrees of (dis)continuity. The crucial question will be to what extent we can observe as strong a structural discontinuity between oE and ME as is argued by Emonds and Faarlund 
(2014, henceforth E\&F; this issue), culminating in their provocative claim that ME developed from Norse and thus qualifies as a North Germanic language.

On the basis of all of the standard reference works on OE, ME and EModE (plus a cross-section of corpus-based studies on historical English syntax of the last 20 years), the following picture emerges. The number of attested WAVE features in $\mathrm{OE}$ is 44, in $\mathrm{ME}$ 66, and in EModE 76, all three historical varieties thus nicely falling within the range of variation among the present-day dialects spoken in the British Isles (37-94 features). Do the data reflect a radical step from OE to ME? Far from it! 95.5 percent of all oE features (42 out of 44) are transferred to $\mathrm{ME}$, and 72.7 percent ( 32 out of 44 features) to EModE. Moreover, almost two thirds of the features constituting the typological profile of $\mathrm{ME}$ were inherited from $\mathrm{OE}$, and the backbone of the typological profile of EModE (8o percent of its 76 morphosyntactic features) is formed by features inherited in almost equal parts from $\mathrm{OE}$ ( 42 percent) and $\mathrm{ME}$ ( 38 percent; this is the proportion of all EModE features which were $\mathrm{ME}$ innovations).

Likewise, ME cannot be shown to have had a stronger lasting impact than $\mathrm{OE}$ on the typological profiles of present-day dialects spoken in the British Isles. Of the twenty most widely attested morphosyntactic features among the ten L1 varieties of English in the British Isles (cf. Kortmann, 2012: 681f.), eight go back to medieval times, six of which as far back as to $\mathrm{OE}$ (e.g., multiple negation and the regularization of irregular verb paradigms) and only two to ME. Focusing on the present-day dialects of the north of England, which of all dialects of England should exhibit the strongest link to the varieties spoken in medieval Northern England, it turns out yet again that the $\mathrm{OE}$ heritage is stronger than the $\mathrm{ME}$ one: while 29 percent of all go Northern features can already be found in $\mathrm{OE}$, only 16.7 percent represent innovations of the ME period. Moreover, of the ten (on a global Anglophone scale) most distinctive features of Northern varieties in the British Isles (besides the dialects of North England, these are Orkney and Shetland English as well as Scottish English, Irish English, and Manx English; Kortmann, 2012: 697), four go back to OE (e.g., yon/yonder indicating remoteness, $b e$ as a perfect auxiliary) and only one to ME. Taken together, then, from the WAVE perspective there is neither a radical step from the typological profiles of $\mathrm{OE}$ to $\mathrm{ME}$, nor is the $\mathrm{ME}$ footprint on later periods of English and the present-day English English dialects heavier than the OE one is. This is also reflected in the NeighborNet network in Fig. 1 (cf. Kortmann and Wolk, 2012: 919f.), which depicts the morphosyntactic (dis)similarity between the three historical varieties of English and the clusters of L1 varieties below them and (dominantly) $\mathrm{L} 2$ varieties above them.

One last remark on E\&F from a dialectologist's point of view: It might be instructive to look at the morphosyntactic variation observable in present-day 


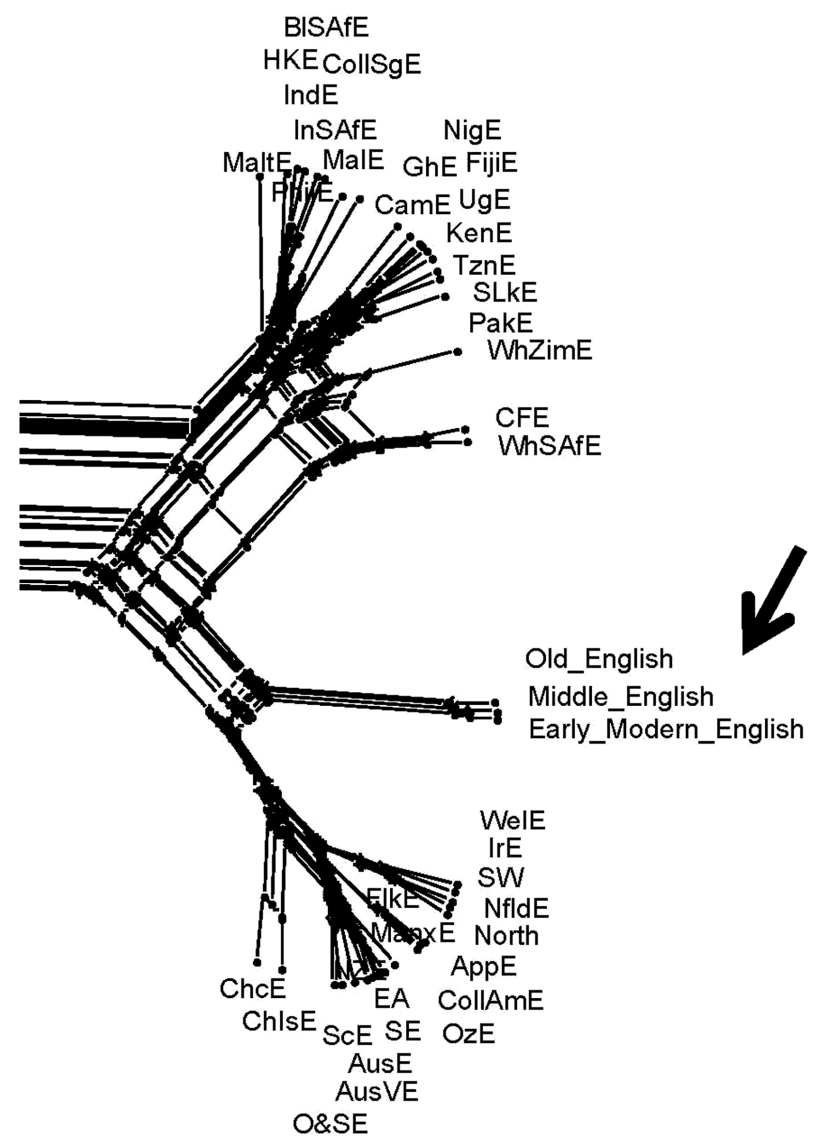

FIGURE 1 WAVE NeighborNet network: OE/ME/EModE relative to the L1 and L2 varieties of English

and historical varieties of continental West Germanic dialects. Here we find a number of features that seem to puzzle E\&F (e.g., in the domains of relativizers, complex subordinators, $d o$-support), where North Germanic influence is clearly out of the question (cf., e.g., Fleischer, 2004, and various contributions in Kortmann, 2004). Why should such developments (as internal, not contactinduced changes or even borrowings) not have taken place in the dialects spoken in medieval England about 800-1000 years ago, too, especially in the North and the East Midlands?

In sum:There is certainly no disagreement on the striking importance of the Viking impact on the development of English grammar in medieval England. E\&F run, however, the risk of overstating their case by neglecting (a) the significant degree of stability from oE to Middle (and even Modern) English grammar(s), and (b) independent developments in the grammars of continental 
West Germanic dialects closely resembling those in $\mathrm{ME}$, which E\&F ascribe to North Germanic influence. The major point this commentator wants to make is that our knowledge about morphological and syntactic properties of English and West (as well as North) Germanic dialects should also be duly considered in the process of syntactic reconstruction and, ultimately, in any attempt to approximate the linguistic situation in medieval England and to find explanations for the structural changes people's speech underwent in the transition period from $\mathrm{OE}$ to $\mathrm{ME}$. My suspicion is that this approach will ultimately lead to the reclaiming of $\mathrm{ME}$ from North Germanic.

\section{References}

Emonds, Joseph Embley and Jan Terje Faarlund. 2014. English: The Language of the Vikings. Olomouc: Palacký University Press.

Emonds, Joseph Embley and Jan Terje Faarlund. This issue. English as North Germanic: A summary.

Fleischer, Jürg. 2004. A typology of relative clauses in German dialects. In Bernd Kortmann (ed.), 211-243.

Kortmann, Bernd (ed.). 2004. Dialectology Meets Typology: Dialect Grammar from a Cross-linguistic Perspective. Berlin/New York: Mouton de Gruyter.

Kortmann, Bernd. 2012. Regional profile: The British Isles. In Bernd Kortmann and Kerstin Lunkenheimer (eds.), 678-702.

Kortmann, Bernd and Kerstin Lunkenheimer (eds.). 2012. The Mouton World Atlas of Variation in English. Berlin/New York: De Gruyter Mouton.

Kortmann, Bernd and Kerstin Lunkenheimer (eds.). 2013. The Electronic World Atlas of Varieties of English 2.o [eWAVE 2.o]. Leipzig: Max Planck Institute for Evolutionary Anthropology. Accessible at http://ewave-atlas.org (accessed March 30, 2016).

Kortmann, Bernd and Christoph Wolk. 2012. Morphosyntactic variation in the Anglophone world: A global perspective. In Bernd Kortmann and Kerstin Lunkenheimer (eds.), $906-936$. 